\title{
A origem das línguas: posições da função-autor e diferentes leituras
}

Eni P. Orlandi

"O passado muda porque é invenção do presente"

(I. Wallerstein)

\section{Introdução}

Ciência e Religião sempre buscaram respostas para duas questões: a origem e o destino (fim) de tudo. Aí se juntam, para nós, duas outras injunções: a da unidade (pureza) e a da diversidade (degradação). Na perspectiva em que nos colocamos tanto as questões sobre a origem como sobre o desaparecimento, quando se trata das línguas, podem-se dar em processos de mistificação, enquanto especulações.

No entanto, podemos, sem dúvida, tornar esse assunto mais interessante se pensarmos, do ponto de vista discursivo, o que de representação e de ciência pode existir nessa relação com a linguagem, quando o pretexto é a pergunta pela origem. Nesse sentido, algumas questões nos chamam a atenção. Por exemplo, a de que a reflexão sobre a origem pode possuir um caráter operatório na teorização da língua. Nesse caso, qual ou quais são eles e em que quadros teóricos e históricos funcionam? Assim como a questão que coloca se origem, gênese e história são sinônimos na abordagem da linguagem. Ao que respondemos prontamente que não.

Além disso, se pensamos a leitura de arquivos, em nossos processos de memória, fica-nos a pergunta de como lemos - interpretamos - os discursos de nossa origem, quando se pensa a língua.

Falta ainda dizer que trataremos de uma situação marcada pela dualidade, pelo equívoco: a questão da origem da língua quando se pensa um país de colonização, o Brasil. Por que equívoco? Porque, na forma ambígua em que se dá essa situação, temos duas faces: a que se estabelece em relação às línguas indígenas e a que se dá em relação à língua imposta pelo colonizador, isto é, o português. E já adiantamos que não supomos que a língua brasileira é resultado da simples junção de uma tradição com a outra.

Como veremos no desenvolver deste trabalho, quando se pensam as línguas indígenas, a relação com a origem das línguas se faz por representação, em narrativas míticas. A origem da língua, quando pensamos o português, desemboca na relação com a colonização e temos assim a relação da língua que falamos com a língua imposta pela colonização, o português. Não se trata de uma narrativa mítica, mas de formas diversas de relação: com os relatos de viajantes e missionários (período da colonização), com o período da gramatização (República, período de descolonização). 


\section{Os Índios e seus mitos de origem}

Entre os Bakairi ${ }^{1}$ diz-se que foi Xixi (o deus sol) quem deu armas de fogo para os brancos e flechas para os índios. Assim também foi ele quem deu uma língua para os brancos que é diferente da língua que deu para os índios. Além disso, e este é um fato interessante, há entre os Bakairi duas línguas: a língua de antigamente, que é de uso exclusivo do pajé, e a língua de hoje falada por todos os índios do grupo. A língua do pajé serve para ele falar com os bichos, com as aves, com as almas etc. Por exemplo, o sapo é metamorfose de um ser do mal, o Kado. Mas nem todo sapo é Kado. Para saber, o pajé conversa com ele e pode distinguir se ele é ou não Kado. Essa língua assegura portanto uma forma de conhecimento só pertencente aos pajés. Essa é a forma de representação desses índios com a língua. Para os Guarani também há as palavras secretas enunciadas apenas pelo pajé. Nos Tikuna, a língua é criada ao lado dos objetos, das danças etc. Já no México, os Aztecas tinham o Deus da palavra; este Deus é, em um paralelo com a mitologia greco-romana, correspondente a Mercúrio, patrono da Comunicação.

Mas vejamos agora um mito indígena brasileiro que fala diretamente da origem da língua. É um mito dos Makurap. Este mito me foi fornecido por uma orientanda, Ivania Neves Corrêa, que trabalha com um mito Tapirapé que é o "caminho da anta" e que na verdade representa a Via Láctea. Mas vejamos o nosso mito Makurap (do sul de Rondônia).

Segundo este mito, no início do mundo as pessoas moravam dentro da terra e só existia uma língua, o Makurap. Até que um dia, um fato inesperado dá início a um novo momento na história dos homens e das línguas. Um relâmpago muito forte parte uma enorme pedra e neste momento nascem dois índios, os filhos da pedra. Chamam-se Waleyat que quer dizer, em Makurap, os filhos da pedra. Eles queriam encontrar outras pessoas mas isso nunca acontecia. Os dois passaram a deixar milho para os animais comerem. Um deles, o mais esperto, fez uma tocaia e viu que uma pedra começou a se erguer. A pedra dava acesso ao mundo dentro da Terra. Era um portal encantado. Várias mãos saíram dela para recolher o milho. Em seguida, depois de algumas peripécias, em que o índio menos esperto fez algumas trapalhadas, o índio mais sábio criou muitas casas. Para estas casas veio muita gente, todos os povos indígenas e até os não-índios. O irmão mais sábio decidiu ensinar às pessoas que vieram de dentro da terra a língua Makurap, que era a sua língua. Para isto pediu a ajuda do outro irmão. Colocaram o pessoal em fila e um foi para um lado e o outro para o outro lado. Quando o irmão mais sábio chegou no meio da fila, viu com desespero que seu irmão menos esperto havia ensinado não só o Makurap mas também as línguas Jabuti, Urudão, Suruí, Tembé, Tupari, português, inglês. Enfim, as línguas de todos os povos do mundo. As pessoas falavam línguas diferentes e já nem se entendiam direito. Como o irmão pudera contrariá-lo tanto! "Não era para ensinar assim, diz ele! Era só uma língua, era só o Makurap”. Em vão o irmão mais sábio ainda tentou ensinar a todos a língua Makurap. Mas já era tarde, as outras línguas já faziam parte da cultura de todos os outros povos.

Quando interpretamos este mito, não há, penso eu, como não fazer um paralelo com a representação da diversidade das línguas e a Torre de Babel. Inclusive porque as línguas acompanham a construção das casas onde vão viver as pessoas que saíram pelo 
Portal encantado do seio da Terra. Na leitura deste mito podemos supor que há vestígios do contato destes índios com o discurso dos missionários, com o discurso bíblico.

Como se vê, portanto, há uma representação de origem das línguas indígenas, que, no caso que apresentamos, a do Makurap, se assemelha ao mito de Babel. Mito que fala da diversidade das línguas, ao mesmo tempo em que afirma a importância de se ter "uma" língua, a sua língua.

Com estes exemplos procuramos referir a forma como os índios representam a origem de suas línguas. Como se pode interpretar esta origem.

Passemos agora para a relação com a língua do colonizador. Dividiremos esta relação em duas: (a) a da inscrição das línguas nos relatos de missionários e de viajantes; (b) a gramatização (a língua brasileira).

\section{A inscrição das línguas nos relatos de missionários e de viajantes no período colonial}

Como eu observava em 1992, ${ }^{2}$ a reflexão sobre o contato entre os Índios e os Europeus, no Brasil, pode nos oferecer indicações interessantes para a compreensão da produção de sentidos divididos entre duas histórias, entre duas culturas. Em particular, o discurso dos missionários e viajantes europeus no Brasil se apresenta como o lugar de uma partilha de sentido onde se pode observar a) o modo como os Europeus sistematizam suas novas experiências e seus conhecimentos produzindo sentidos onde ainda não havia sentido estabelecido (para eles) e, b) a construção de um discurso "outro", isto é, um discurso sobre a origem, para os brasileiros. Assim, esse universo discursivo guarda sempre esta pluralidade de sentidos, administrados muitas vezes pela relação de forças estabelecidas no confronto desses dois mundos, o Velho e o Novo, com suas diferentes impressões históricas e de representação, produzindo, no mínimo duas leituras, constitutivas de dois sujeitos histórico-sociais.

Nós vamos mostrar aqui a nossa perspectiva, a dos que, naquela época, são chamados "Amériques". Há ainda a dizer que esta complexidade está no modo como se apresenta este discurso. No material que vamos analisar há a aliança de três discursos: o da ciência, o da política social e o da religião. Portanto há a entrada para três formas de leitura dependendo do ângulo pelo qual entramos. Embora os outros dois não cessem de fazer sentido. Estes três discursos são modos de domesticar a diferença: a ciência, pelo conhecimento, a política social, pelo processo de mediação e a religião, pela Salvação. A ciência torna o novo mundo observável e sua cultura lisível, a política social o torna administrável e a religião o torna assimilável. ${ }^{3}$

Cabe perguntar, em relação à língua, como ficam suas formas de representação.

Que línguas apagamos para ter UMA língua, a nacional? Para compreender este apagamento, nossa análise procurou tornar visíveis certos traços da história da relação entre o tupi e o português.

Distinguimos duas concepções de língua, a imaginária e a fluida. A imaginária é a que os analistas fixam com suas sistematizações e a fluida é a que não se deixa imobilizar 
nas redes de sistemas, de normas e de fórmulas. Há vários modos de produzir a língua imaginária e seus produtos são bastante diferentes: a língua mãe (o indo-europeu), a língua ideal (a lógica), a língua universal (o esperanto) e, em nosso caso, o tupi-jesuítico (língua franca) e o português standard (língua nacional). Os missionários disciplinaram o tupi para instalar seu poder de controle sobre os Índios e seu poder de negociação com o governo português. A disciplinarização teórica, isto é, a construção de um saber a propósito das línguas dos Índios mistura-se aqui com a disciplinarização exercida na prática de linguagem dos missionários no curso de seu confronto com os Índios. Eles produzem uma língua imaginária que adquire no entanto uma realidade enquanto projeto do Estado porque ela se constitui em língua de uso geral.

Observando os relatos dos missionários, pode-se ver que o modo como obtêm-se os dados e os apresentam em seus relatos já é uma forma de fabricar uma língua e instituir uma relação determinada com ela e seus locutores. Os padres, os viajantes, os pesquisadores, no próprio momento em que falam da língua dos Índios, elaboram uma etnografia em que a representação da língua era um componente fundamental. Se tomamos a perspectiva da história das ciências, podemos dizer que a forma como se conduziu a pesquisa sobre as línguas dos Índios e, sobretudo, o modo como se produziu a coleta de dados, estigmatiza uma língua indígena incapaz de desenvolvimento interno, matéria inerte, sem história. Uma língua que não é capaz de influenciar as formas das outras línguas, sendo ela própria representada como rígida, humilde, pobre. Nos relatos se constrói assim um modo de conhecimento das línguas ameríndias. Há, assim, um modelo de descrição, uma "disciplina" que se inscreve no interior dos relatos e nas formas do catecismo, das gramáticas, dos dicionários e mesmo nas compilações poéticas (canções) dos missionários.

Quanto aos viajantes desta mesma época (Hans Staden, 1557, Jean de Léry, 1578, A. Thévet, 1557), a imagem produzida sobre a língua não difere muito da dos missionários. Suas finalidades são talvez diferentes no imediato, por se produzir um conhecimento menos imediato, menos utilitário. Jean de Léry, por exemplo, fazia anotações sobre a língua. Há aí o embrião de uma observação científica. Mas em geral eles se servem de intérpretes ou de informações/conhecimentos daqueles que os precederam.

Eles utilizam uma técnica de referência à língua que se repete: eles constroem uma situação de linguagem, produzem uma palavra, uma frase ou mesmo um texto em língua indígena e a traduzem juntando comentários e interpretações. Este procedimento nos mostra que: a) as referências à língua servem a uma finalidade didática nas situações de contato; b) a tradução contribui para a assimilação de uma língua à outra (européia) e à sua (língua indígena) desqualificação. Eles não produzem uma lingüística ou uma gramática mas uma etnografia. Ainda que não seja um conhecimento codificado estritamente ao modo científico, o saber produzido pelos relatos é o germe de uma ciência que se explicita no século XIX (ou mesmo antes, por exemplo, com as Considerações de De Gerando). Os relatos podem ser lidos como uma obra esclarecedora (informar sobre o Novo Mundo) e como um escrito que tem uma função edificante (reafirmar a importância da cultura européia e cristianizar o mundo). 
Até este momento, no período colonial e no início do século XIX, o interesse do estudo das línguas é dos estrangeiros. É com D. Pedro II, com o romantismo, que esta situação começa a mudar. E com a independência teremos os Brasileiros olhando para sua própria cultura e produzindo seu próprio conhecimento como veremos a seguir.

\section{Os viajantes e cientistas do fim do século XVIII e XIX}

Este é um interesse que deixa de ser religioso para ser um interesse que visa saber como é o Brasil. É o interesse dos naturalistas.

Os discursos sobre o Brasil, produzidos no contato dos Europeus com o Novo Mundo, sofreram, no século XVIII/XIX uma transformação radical. Com o neocolonialismo há o retorno dos relatos, nas diversas reimpressões dos textos do século XVI e XVII mas outra forma de discurso se apresenta como dominante: a descrição. Quanto a este aspecto é interessante observar que a ambigüidade do uso indistinto, nos séculos XVI e XVII, pelos missionários franceses, das palavras rapport/relation para relato (récit) atesta a fragilidade dos limites entre ciência e ficção (representação), literatura. No século XVIII, a distinção rapport/relation já prenuncia a relação formal que se firmará no século XIX entre literatura e ciências humanas. São dois modos de leitura que se apresentam em suas diferenças: relatório e narrativa.

A passagem narração/descrição, na história dos discursos sobre o Brasil, e, entre eles, sobre a língua, é um largo passo que diferencia a forma de tratar a realidade brasileira. Deixamos de ser apenas uma especificidade cultural para termos um lugar no discurso da ciência. Em relação às línguas, se na época das descobertas se procurava aproximá-las do latim, interferindo nelas, no século XIX, interessam novas variedades, novas categorias, em suma, a classificação das espécies. Trata-se de traçar os contornos do patrimônio universal (natural): determinar, descrever, tornar disponível, recensear a presença das diferentes espécies e apreciar suas qualidades naturais. Construir bancos de dados disponíveis.

Podemos citar o príncipe Wied Neuwied - que chegou mesmo a levar um índio para a Alemanha para que um especialista estudasse sua língua - ou St. Hilaire que considerava a importância dos modos de observação tanto das plantas como das línguas que, segundo ele, podiam ser mais ou menos sistemáticas. Finalmente, podemos dizer que se tratava da constituição de bancos de dados (que era um grande interesse da Europa neste momento). Os modos como se observam as línguas - fazendo listas de palavras, por exemplo - e as considerações sobre a forma de obterem os dados estabelecem um modelo que será o da pesquisa de campo e que, no Brasil, se mantém até hoje na Lingüística Antropológica. Pesquisa em que o imaginário e a ciência se tocam.

\section{O século XIX: a independência do Brasil e a gramatização de sua língua}

O que significa no Brasil do século XIX ser autor de gramática? ${ }^{4}$ 
Ser autor de gramática no século XIX, no Brasil, é assumir a posição de um saber lingüístico que não reflete meramente o saber gramatical português. Nesse momento, o da irrupção da República, não basta que o Brasileiro saiba sua língua, é preciso que, do ponto de vista institucional, ele saiba que sabe. ${ }^{5}$ A gramática, dessa perspectiva, é o lugar em que se institui a visibilidade desse saber legítimo para a sociedade brasileira. Ao deslocar para o território brasileiro a autoria da gramática - a gramática continua na maior parte das vezes a se chamar Gramática Portuguesa (cf. Júlio Ribeiro, 1881) ou Gramática da Língua Portuguesa (cf. Pacheco Silva e Lameira de Andrade,1887) - o que os gramáticos brasileiros estão deslocando é a autoridade de dizer como é essa língua. Ser autor de uma gramática é ter um lugar de responsabilidade como intelectual e ter uma posição de autoridade em relação à singularidade do português do Brasil.

Esse saber pode e deve estar relacionado à produção internacional. Nesse sentido, não há apenas "influência", reprodução de idéias estrangeiras no Brasil. Se pensarmos em termos discursivos, temos relações de sentidos que se estabelecem entre o português do Brasil e o de Portugal e veremos nessas "influências", nessas filiações teóricas, um processo de re-significação, de historicização, tanto da língua quanto do saber sobre ela.

A unidade do Estado se materializa em várias instâncias institucionais. Entre essas, a construção da unidade da língua, de um saber sobre ela e os meios de seu ensino (a criação das escolas e seus programas), ocupa posição primordial. A gramática, como um objeto histórico, um instrumento lingüístico, disponível para a sociedade brasileira, é assim lugar de construção e representação dessa unidade e dessa identidade (Língua/ Nação/Estado), através do conhecimento.

Ao trazerem o gesto da autoria para si, os primeiros gramáticos brasileiros como Júlio Ribeiro, João Ribeiro, Maximino Maciel, Lameira de Andrade e Pacheco Silva, entre outros, estão participando da construção do Estado brasileiro. A história da língua, da produção de objetos/instrumentos que representam para a sociedade o conhecimento sobre ela, assim como a dos que a praticam (os cidadãos), estão inextricavelmente ligados. O processo de gramatização brasileira do português constitui assim um saber sobre a língua e suas singularidades e processa a historicização da língua no território nacional, brasileiro. Júlio Ribeiro, por exemplo, recusa a tradição estabelecida por Jerônimo Soares Barbosa ao definir a gramática como "exposição metódica dos fatos da linguagem", considerando que o que Jerônimo Soares Barbosa faz é uma metafísica. Ao fazer isso ele faz um gesto fundador que constrói uma filiação à qual os gramáticos brasileiros farão referência sistemática.

Desse modo, a identidade lingüística, a identidade nacional, a identidade do cidadão na sociedade brasileira traz entre os componentes de sua formação a gramatização no século XIX. Ser autor de gramática é parte essencial dessa história. A posição sujeito autor do gramático brasileiro acumula os dois sentidos: o de produção de um saber sobre a língua e o gesto de apropriação legítima dessa língua.

A gramatização legitima também, ao mesmo tempo, a relação do brasileiro com a escrita. Temos uma língua, uma gramática e sujeitos brasileiros da nossa escrita. Com a autoria dos gramáticos (e os literatos, os historiadores, os políticos brasileiros etc) o 
século XIX é, entre outras coisas, um momento intelectual definidor na direção de se pensar a língua, suas instituições e seus sujeitos, assim como a escrita ("Escrever-se como se fala no Brasil e não como se escreve em Portugal”, diz Macedo Soares). Evidentemente isto tem reflexos sobre as formas da leitura, já que esta representa uma relação determinada com a língua em que conta seu estatuto e sua legitimidade nacional.

Com a Independência, em 1822, o Estado brasileiro se estabelece e a questão da língua se evidencia. Um exemplo disto é o fato de que, em 1826, já se coloca a discussão, a partir de um projeto proposto no Parlamento, portanto por meio do poder constituído, de que os diplomas dos médicos devem ser redigidos em "linguagem brasileira". Nos anos que se seguem e com a vinda da República, tanto o Estado como a questão da língua brasileira se configuram mais decididamente e a emergência das gramáticas no século XIX atesta o vigor dessa época e dessa relação língua e Estado.

A gramatização do português brasileiro, além de ser um processo de construção de um saber sobre a língua nacional, tem como conseqüência algo mais substancial e definidor: a constituição de um sujeito nacional, um cidadão brasileiro com sua língua própria, visível na gramática. Individualiza-se o país, seu saber, seu sujeito político social e suas instituições.

Após esta fase, já nos inícios de 1900, esse cenário se modifica.

\section{O Gramático e o Lingüista}

Em 1900, o Estado brasileiro já se estabeleceu com clareza e é ele próprio a garantia da nossa diferença em relação a Portugal. Institucionaliza-se a relação do brasileiro e do Brasil com a língua nacional e a nossa sociedade organiza-se diante de suas necessidades de representação científica, criam-se faculdades, já que a instituição escola adquire maturidade. Então, as gramáticas já não têm a função de dar forma aos difíceis limites da identidade brasileira, só o de mantê-los em sua configuração, o que implica em distinguir quem sabe e quem não sabe a língua corretamente. Surgem então numerosas gramáticas, cujas diferenças já não se referem a autorias de gramáticos em suas filiações mas dizem respeito a diferenças descritivas e analíticas: filigranas de diferenças na análise da oração e de complementos, adjuntos x ou y etc. Passa a haver uma profusão de gramáticas. Nessa profusão de autoria dos gramáticos, começa o apagamento da materialidade da autoria praticada no século XIX, que garantia a construção conjunta de uma língua e um Estado nosso. Com a NGB (1959) é uma comissão que, a partir de um decreto do Estado, estabelece a homogeneidade de uma terminologia que desautoriza as variadas posições dos gramáticos. Com a NGB o Estado brasileiro toma em mãos a administração da relação institucional do Brasileiro com a língua nacional, via gramática, pela uniformização da terminologia. Depois desse deslocamento, a autoria do saber sobre a língua deixa de ser uma posição do gramático e será patrocinada pelo lingüista. É este que dará a caução ao saber do gramático. O gramático por sua vez passa a ter a função de guardião da norma gramatical. Seu conhecimento, na partilha de quem sabe e de que não sabe a língua, divide o que é e o que não é da norma. 
Como conseqüência, em face da relação com a norma, produz-se um deslizamento ideológico, sobretudo nas escolas, que é o imaginário da preservação da pureza da língua. E, no equívoco da ideologia da colonização, escorrega-se facilmente para a representação de que a língua verdadeira, a pura, é a língua portuguesa, de Portugal, sendo a nossa um português mal falado. Esquece-se desse modo todo o processo de gramatização. Passa-se, assim, em retorno, do conhecimento para uma representação imaginária, herdada da colonização.

\section{Observações Conclusivas}

Para finalizar, gostaria de dizer que há ainda, entre os índios, um fato interessante, face a esta questão da relação entre ciência e representação mítica. Este fato, como veremos, nos mostra que não há um sentido só que vai da representação para a ciência, mas um movimento contínuo entre ciência e representação.

Os índios têm um mito em que eles representam a Escola e com ela a escrita. Ou seja, uma representação de como a ciência entrou para suas vidas. Obtive este mito através de José Ribamar Bessa Freire ${ }^{6}$.

\footnotetext{
"Contam os andinos que Deus teve dois filhos: o Inka e o Sucristo. Inka, por sua vez, teve dois filhos e Sucristo ficou com muita inveja. A lua para ajudá-lo deixou cair um papel com coisas escritas nele. Sucristo, querendo assustar o irmão, mostrou-lhe o papel. Inka ficou com tanto medo que fugiu para longe. Como não podia pegá-lo, Sucristo começou a chorar. Então o puma reuniu outros pumas, perseguiu Inka e, enquanto ele agonizava pois não conseguia comer, Sucristo matou a mulher dele. Depois mandou construir duas Igrejas, onde mora. Quem ficou feliz quando soube da morte foi Ñaupa Machu, que vivia numa montanha chamada Escola. Quando Inka era vivo ele era obrigado a ficar escondido e agora podia aparecer. Atraídos por Naupa Machu os filhos de Inka foram a Escola em busca de notícias dos pais. Mas Ñaupa Machu queria era comê-los. Os meninos desconfiados, fugiram, e desde essa época as crianças são obrigadas a ir para a escola. Mas como o dois filhos de Inka, elas não gostam da Escola, fogem dela. Onde estão os dois filhos de Inka? Dizem que quando o mais velho estiver crescido vai voltar. Este será o dia do Juízo final. Mas não sabemos se ele poderá mesmo voltar. As crianças, os meninos, devem procurá-lo, já estão procurando, talvez o encontrem. Mas onde ele pode estar? Talvez em Lima, talvez em Cuzco, quem sabe? Se não o encontrarmos, ele poderá morrer de fome como o Inka seu pai. Será que ele vai morrer de fome?"
}

Ora, aí temos a representação de uma instituição do conhecimento - a Escola e seu instrumento principal - a escrita. Como disse mais acima, não há uma direção só em que passamos da representação para a ciência mas sim um movimento contínuo entre ciência e representação.

Podemos dizer, em relação às indagações postas no início, que a questão de origem possui um caráter operatório na teorização da língua. Nesse caso, que exploramos em nossa exposição, elas funcionam no quadro teórico da análise de discurso e a história das idéias lingüísticas, no trabalho de arquivo. Pensando assim no método que este objeto supõe, é que podemos apreender o fato de que há um jogo na relação entre ciência e 
representação (em nosso caso, mítica). Além disso, países de colonização, dada a necessidade de, na sua história lingüística, dispor de um processo de descolonização, necessitam de instrumentos teóricos diferenciados - no nosso caso, discursivos - para poder apreender os efeitos de sentidos produzidos nessa relação entre conhecimento e imaginário.

Os objetos simbólicos de representação de nossa origem põem em circulação diferentes discursos - o mítico e o da ciência - com seus diferentes regimes de validade, seus diferentes modos de leitura. Mas essas diferentes leituras - que produzem efeitos de sentidos que funcionam na duplicidade, constituindo o que podemos chamar de identidade da ordem do equívoco - mais do que simples efeitos de leitura, estão na base da produção de posições sujeito diferentes com suas diferentes inserções sociais na história e na ideologia.

Resta finalmente dizer que a leitura se dá aí a partir de diferentes relações com a memória. Pensando-se estes materiais em suas diferenças enquanto materiais que têm sua historicidade. Como tenho proposto, ${ }^{7}$ podemos distinguir a memória discursiva, que é o interdiscurso, a memória afetada pelo esquecimento. Aquela em que algo fala antes, em outro lugar, independentemente, como diz M. Pêcheux (1975). E temos ainda o arquivo $^{8}$ propriamente ou a memória institucional, que é aquela que não esquece, ou seja, aquela que as Instituições (Escolas, Museus, Eventos etc) praticam, alimentam. E temos ainda o que chamo memória metálica, ou seja, a produzida pela mídia e pelas novas tecnologias de linguagem. A memória da máquina, que não se produz na história e na sociedade mas por um constructo técnico (televisão, computador etc). Pois bem, nos casos que analisamos, trata-se da relação da memória de arquivo e a memória discursiva. E, como dissemos, as diferentes formas de leitura - relacionando-se com o arquivo ou com o interdiscurso, ou com ambos ao mesmo tempo - podem resultar em novos gestos de interpretação desses materiais que apresentamos em nossa exposição, propiciando ao Brasileiro uma maior compreensão da forma histórica da posição sujeito que ele constitui.

Notas

\footnotetext{
${ }^{1}$ Cf. SOUZA, T.C.C. de (1994) Discurso e Oralidade: um estudo em língua indígena (Bakairi), Tese de Doutorado. Programa de Pós-Graduação em Lingüística. Campinas: IEL, Unicamp.

2 ORLANDI, E. P. (1992) “Les Amériques et les Europeens: un clivage de sens ou La danse des gramaires", In: Cabiers de Praxématique.

${ }^{3}$ ORLANDI, E. P. (1990) Terra à Vista. São Paulo: Cortez/Unicamp.

${ }^{4}$ ORLANDI, E. P. (2002) Lingua e Conbecimento Lingüístico. São Paulo: Cortez.

${ }^{5}$ ORLANDI, E. P. (1996) Interpretação. Petrópolis: Vozes.

${ }^{6}$ FREIRE, J.R. Bessa (2001) "A representação da escola em um mito indígena”, In Teias. Rio de Janeiro: UERJ, ano $2, n^{\circ} 3$.

${ }^{7}$ ORLANDI, E. P. (1996) op. cit.

${ }^{8}$ PECCHEUX, M. (1981) “Ler o Arquivo Hoje”, In Gestos de Leitura. Campinas: Unicamp.
} 


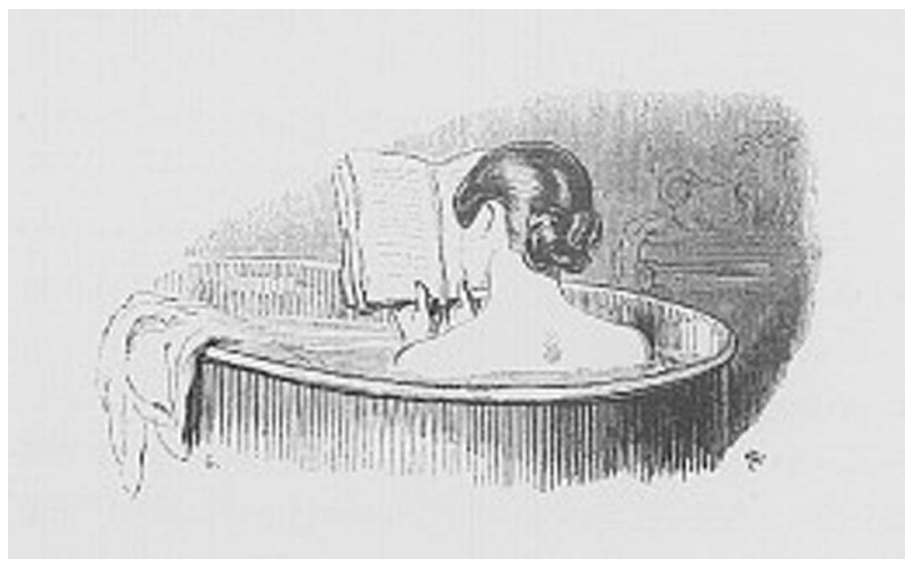

